\title{
Industry of Acrylic, Woven - Patterned Blanket in - (Kadhimiya \& Fateh) Factories for (2009-2015) A Comparative Study
}

\author{
Assistant Pro. Dr. Intesar Hassoon Redha Al-Salamy ${ }^{1}$
}

\begin{abstract}
The fabric industry is one of the vital field for many of third world countries, it has great influence at the economic growth, fabric field has major role in the infrastructure of Iraqi industries ,so to step up a head we must expand this kind of industry and produce high quality goods, like many other fields , the fabric industry is a blending of two important factors, agriculture \& animal resources, the fabric industry represent start push towards the industrial transformation process, Therefore, the study consist of two topics, the first one explores the historical evolution of the general company of fabric and leather industries. (Kadhimiya \& Fateh) factories belongs to the general company.

The second topic shows the statistical and quantity analysis for elements of industrial localization of blanket industry in Baghdad for (2009-2015), the result of study indicate there are many indicators make these factories are Ideal and adequate to expand and flourish in area of study, those indicators are: the availability of qualified workers, positive statistical results, finally the study was culminated by conclusions and recommendations .
\end{abstract}

Keywords: Fateh Factory, Kadhimiya Factory, Acrylic-patterned blanket, Woven blanket

\section{Introduction}

The industry represent the cornerstone of the economic development in the geographical region that became the land of emerging a lot of social and economic development . all these elements will lead to tremendous changes, therefore the fabric industry is one of the oldest industries that the man knew it since the evolution, the fabric industry had linked with life's community and people developing, in common , the area of study has special interest because it reveals first type of transformation industries ,it is worth mention that first fabric factory in Iraq was established early last century, due to the importance of fabric industry we made this study.

\subsection{The problem of the study:}

1. What are the element of industrial localization of acrylic woven - patterned blanket industry for (Kadhimiya \& Fateh ) factories?

2. Are there any differences in the industrial localization between both factories ( Kadhimiya \& Fateh ). 


\subsection{Hypothesis of study}

There are many natural, human and economic elements for industrial localization of (Kadhimiya \& Fateh ) factories, and we'll explain in detail the human economic elements and it's influences on these factories

\subsection{Limits of the study}

The limits of the study encompass two dimensions as it follow:

1- local dimension : represent the area of the study in Kadhimiya city which situated in Kadhimiya municipality services that cover $(862,765) \mathrm{km}^{2}$.

2- Time dimension: display the statistical analysis for data concern two factories for (2009-2015).

\subsection{Methodology of the study}

Adopting correct and certain method is the right way to reach the desired goals, the researcher adopt descriptive and statistical methodology to study the blanket industry in the area of study, and analyze all the data altogether to the scheduled goals.

\subsection{Tools of the study} follow:

Collecting the information and data concern the study will be performed as

1- The paper work: the researcher count on the local and foreign books and references related to the study.

2- Field study: Refer to the general company of fabric and leather industry for Kadhimiya \& Fateh factories .

3- Analyzing data and information: by using scientific- logical and statistical manners to measure the industrial- economic variables, in addition the data will be processed by statistical program (Spss) and (Excel) to perform and execute charts and maps that might illustrate the industry's requirements.

\section{First Topic :}

\subsection{The Historical Evolution of Kadhimiya \& Fateh Factories:}

Since the subject of the study ( Kadhimiya \& Fateh factories) concern the general company for fabric and leather industries, we should take a look at the profile of the company :

The company was established in 1926 titled (factory of Fattah Basha) located in Kadhimiya city ,the company is a specialized for industrializing the mechanic carpet and floor rugs, blankets - fabric with different size and high quality ( Field study,2016).

\subsection{Steps of company establishment historically:}

- (Fattah Basha) factory was established in 1926.

- (Fattah Basha) factory was nationalized in 1964, after that it got another name (the general company for Spinning and woolen fabric) .

- In 1971 the factory (Shuhedaa Al Jaish ), located in (Muasker Al-Rasheed) and Aadhemia factory were merged altogether . 
- In 1987 the general foundation for national fabric was merged with the general foundation for woolen fabric which located in Erbil provinces - north of Iraq.

- In 1997 these two blended foundations got a new name and it was (the General foundation for national wool industry) .

- In 1/1/2016 the foundation mentioned above was merged with (general company for leather industries) to be under new title (the general company for fabric and leather industries)

\subsection{The company encompass several factories}

You can see the geographical distribution for the factories of the company as it. explained in the Map (1). ( Field study,2016).

\section{Map(1)}

Geographic distribution for the factories of the State Company of Textile and leather Industries in Baghdad for the year 2015

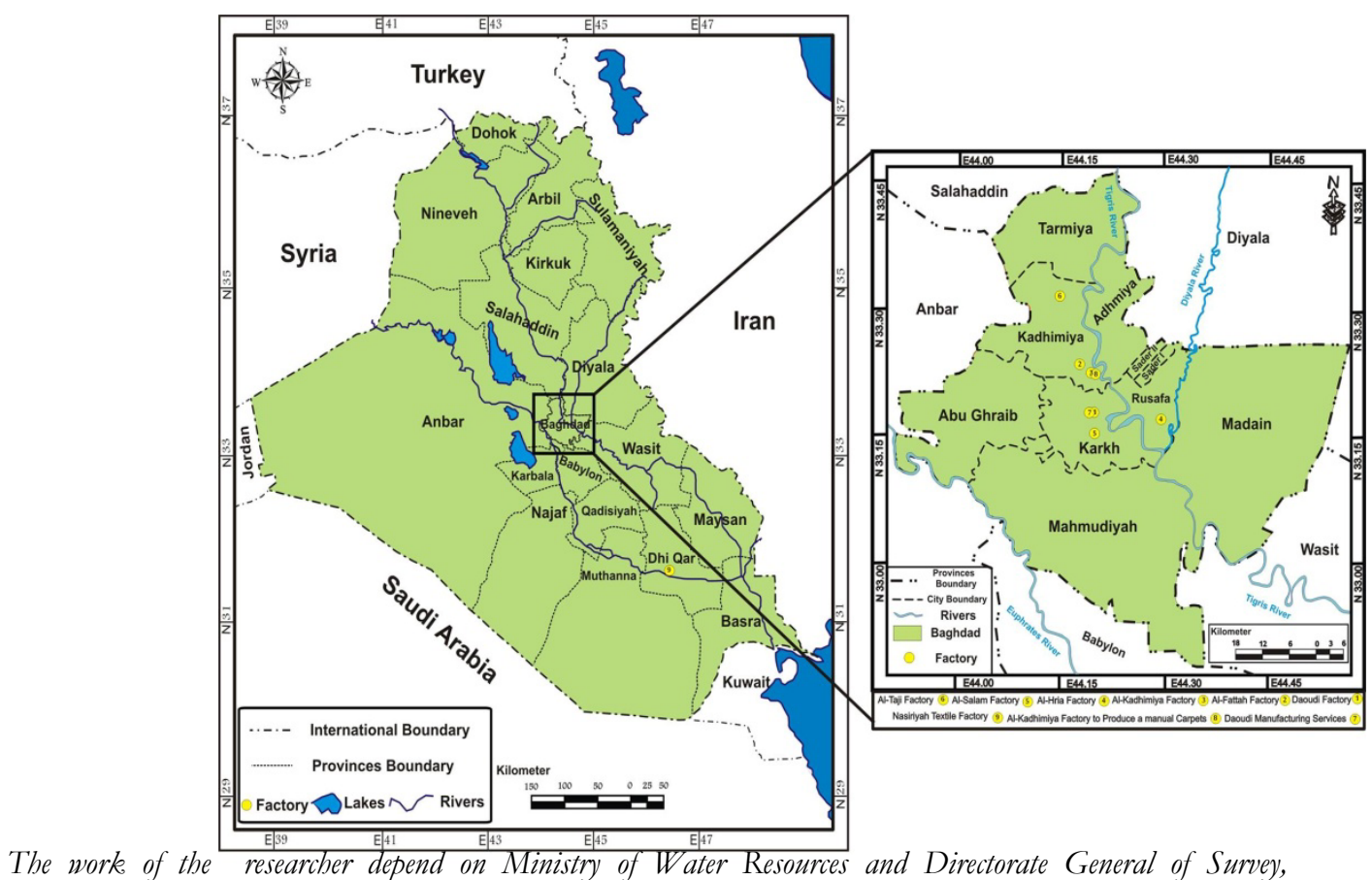

Department pf Maps, Kadhemiya district map, Measure: 1/10000 ,2010.

1- The factory of mechanical carpet for patterned carpet production in Dawoodi zone was founded in 1970.

2- (Fateh factory) for fabrics and woven blanket production was founded in 1975 in Kadhimiya city- Muheet Street. 
3- (Nasyria factory) for fabric and woven blanket production was founded 1979 in (Thee Qar) province.

4- Kadhimiya factory for acrylic - patterned blanket production was established in 1975 in - Akkad - Street.

5- Hurria factory for fabric and woven blanket production, was established in 1954 , in New Baghdad- on the way of (Muasker Al-Rasheed) , this factor produced military fabrics .

6- Spinning and porous carpet factory was established in - Al Salam - district in 1951 to produce Al jooht fabric (carpet ground), the factory capacity got expended in 1990 to produce high quality carpet with its two kind: knot free carpet (open surface carpet) and knotted carpet (knotted rough carpet) .

7- (Tahji factory) in Tahji district was founded in 1974 for washed and dyed Iraqi wool production.

8- Factory for engineering services in Dawoodi zone to supply spare parts upon request of other factories, whether or not belong to the company

9- Handmade carpet factory in Kadhimiya city -Akad Street, was founded in 1971.

The current products for the company:

- Jakard acrylic blanket with variable patterns for 1 or 2 persons.

- Doby woven acrylic blankets, 1 person size (square pattern).

-Etched acrylic blanket, 1 person size .

- Patterned carpet (Baghdad - Babel) with different sizes .

- Acrylic, porous ,plain carpet, : knot free carpet (open carpet) and knotted carpet (rough carpet).

\subsection{Profile of Fateh factory( Field study,2016).}

The factory was established in 1975 in Kadhimiya city - Muheet Street, as it explained in map (2), it was built to produce blankets and local ,mixed woolen fabrics, after the events of 2003 (change of regime) the factory had stopped using local fabrics during blankets industry.

Due to the shortage of local fabrics, the factory had sought another resource, and started to deal with imported fabric like (polyester and acrylic), after 2003 the factory was expanded and updated to open up new production lines to go along with and keep up with modern and high quality products of the world nowadays, the upgraded lines are fellow:

1. The Chinese (Reefa) system, consist of (20) machines linked with computer system provided with specific programs.

2. Belgian (Jakard) system, consist of (8) machines, with capability of designing feature supervised by computer unite.

3. Italian system machine for (making inscription on carpet surface), consist of (4) machines.

4. Italian shaving machine, (2) machines.

$\operatorname{Map}(2)$ 


\subsection{Location of Al- Fattah and Al- Kadhimeya Factories}
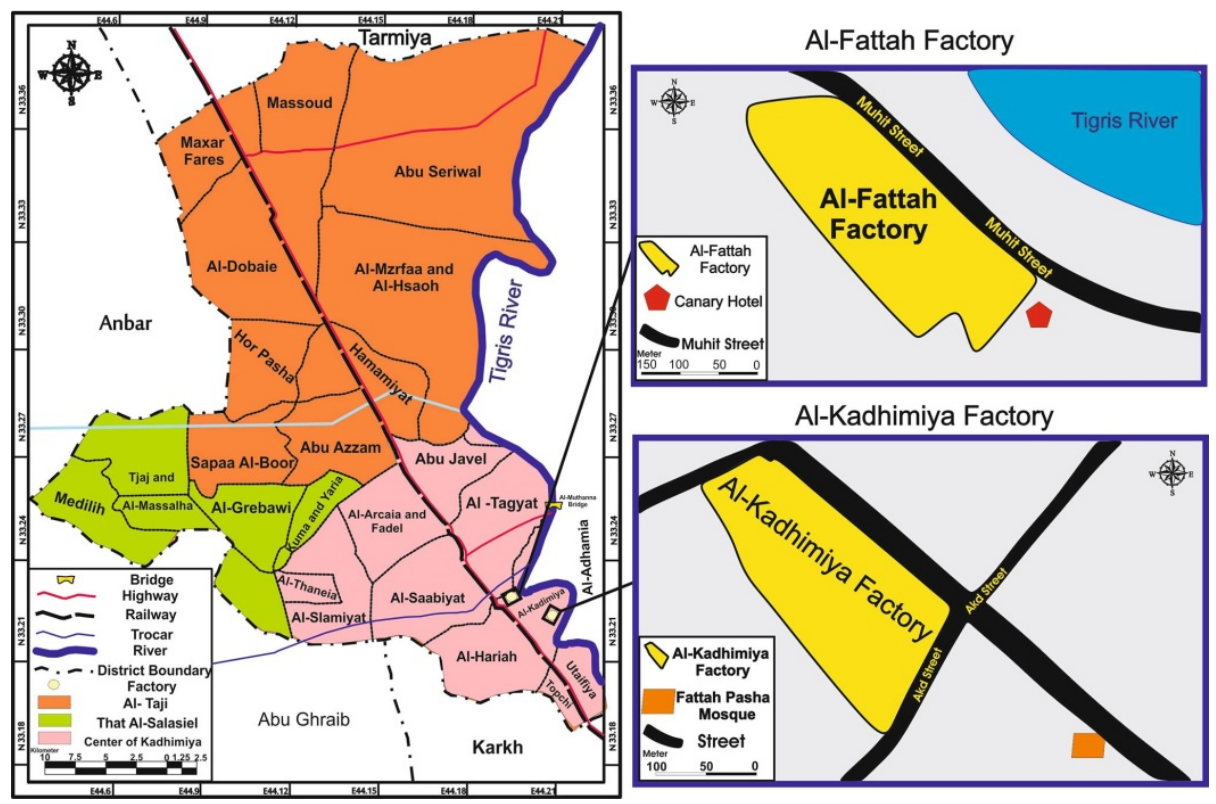

The work of the researcher depend on Ministry of Water Resources and Directorate General of Survey, Department of Maps, Kadhemiya district map, Measure: 1/10000,2010.

The functional structure of Fateh factory, as it illustrated in figure (1)

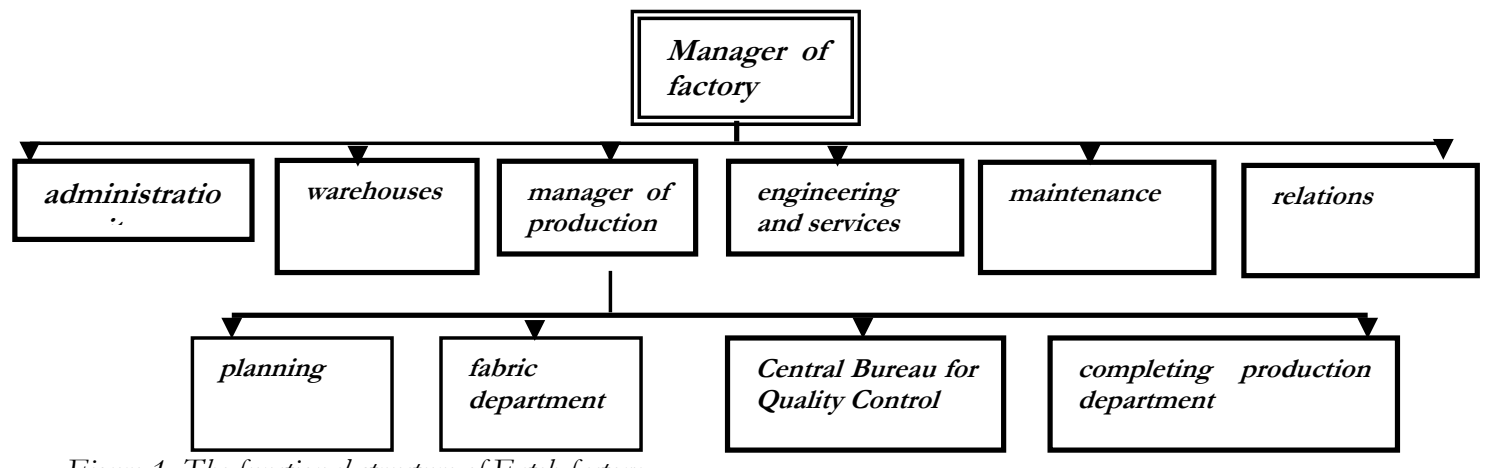

Figure 1. The functional structure of Fateh factory

3. The field study of Fateh factory, planning department, unpublished data.

\subsection{Period of production of Fateh factory:}

First case: In case of the spinning department is working to produce local acrylic yarn.

First: spinning department, Contain as follow (Field study,2016):

1. Receive raw materials from warehouses. 
2. Preparations of spinning department (feeding), (1) sets.

3. (Carding machines), (4) sets.

4. spinning machines, (5) sets.

5. auto corner machines, (1) set.

Second : Tufting machines : Contains as follow (Field study,2016) :

1. Tufting machines, (1) sets.

2. Embroidering machine, (4) sets.

Third: finishing department, consist of several sets .

1- Machines of producing upper layer (carpet surface layer) there are two kinds:

A- Italian machine, (2) sets.

B- Japanese machine, (5) sets.

2- Shaving and polish machine, (2) sets.

3- Auto sewing machine, (1) set.

4- Sewing machines .

Fourth :All the accomplished products will be delivered to the warehouses.

Fifth: All the steps should be supervised by Central Bureau for Quality Control to keep the standardization of products.

Second Case: If the factory working on imported yarn acrylic the spinning department will be ceased instead the imported yarn acrylic will be directed immediately to the tufting department and this is what we adopted for the time being

First : Tufting department, include as follow: (Field study,2016).

1- Tufting machines, (5) sets.

2- Embroidering machines, (4) sets.

Second: Finishing department, consist of several sets.

1- Machines of producing upper layer (carpet surface layer), there are two kinds:

A- Italian machine, (2) sets.

B- Japanese machine, (5) sets.

2- Shaving and polish machine, (2) sets.

3- Auto sewing machine, (1) set.

4- Sewing machines .

Third : All the accomplished products will be delivered to the warehouses.

Fourth: All the steps should be supervised by Central Bureau for Quality Control to keep the standardization of products. 


\section{Profile of Kadhimiya Factory: : (Field study,2016).}

It was established in 1975 in Kadhimiya city , Akad Street, as it illustrated in map (2), the factory was built by (Marobiny), Japanese company for acrylic blanket industry, the estimated capacity production is (1) million blanket per year, first production was launched in $1 / 11 / 1976$, the raw materials used during the production process are as indicated below:

1- Industrial material (acrylics)

2- Canvass base

3- Ribbon of covering blanket edges.

The factory has a good strategic location, it situated in center of Baghdad, the factory lays in sacred area (Kadhimiya) where tens of thousands people visit the shrines of two Imams (Musa Al Kadhum \& Muhammed AL Jawad) (peace upon them), the religious tourism grant Kadhimiya city an exceptional status, moreover Kadhimiya city consider as core of commercial activities, the factory area is $(28000) \mathrm{m}^{2},(16083) \mathrm{m}^{2}$ is occupied by buildings, and (4534) $\mathrm{m}^{2}$ is dedicated for warehouses while the rest of the area, which is (7383) $\mathrm{m}^{2}$, meant for (Direct marketing - Garage - administration of factory and personnel and the necessary services such as medical care unit, - WC- and green yard around the factory, as for the functional structure for Kadhimiya factory is displayed in figure (2) as for the actual services of the factory are as follow: (Field study,2016).

1- electrical power

Design prods $=2.8 \mathrm{mw}$

Available prods $=2.4 \mathrm{mw}$

electricity: transformer

Qty $=3$ phase

capacity $=1 \mathrm{MVA}$

input voltage $=11 \mathrm{kv}$

output voltage $=38 \mathrm{ov}$

2- water.

national ride $=2.8=2.8 \mathrm{mw}$ from supplying station (Al-Zahraa supplier)

generator type: G.E.C. /2MW

tap water $(50 \mathrm{~m} 2 / \mathrm{hr})$

doe drinking \& utilities: $10 \mathrm{~m} 2 / \mathrm{hr}$

industrial water (soft water): $40 \mathrm{~m} 2 / \mathrm{hr}$ 


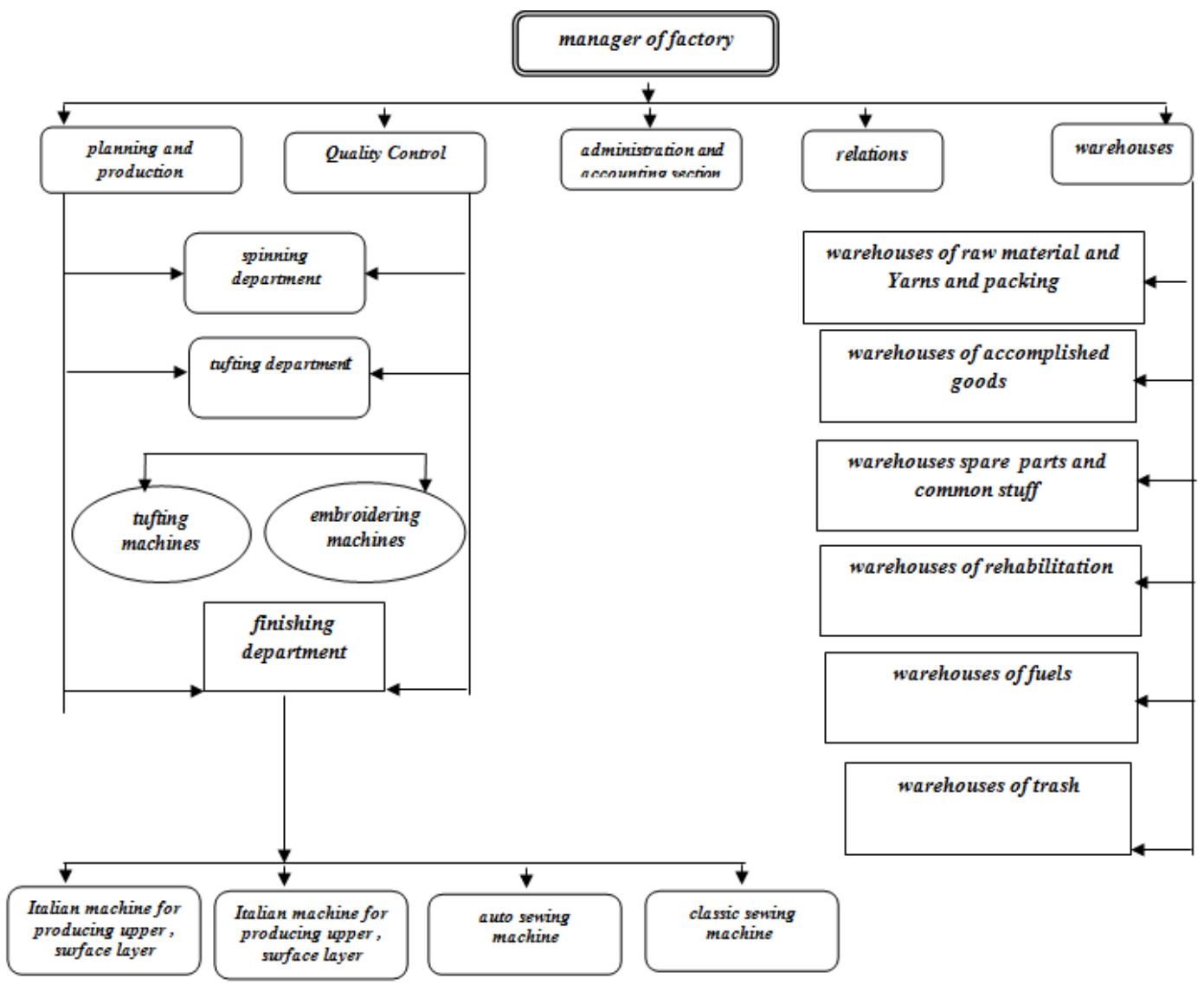

Figure (2) ( Field study,2016)

Functional structure of Kadhimiya factory

\section{Second Topic}

Statistical quantity analysis for industrial localization elements in Baghdad for (2009-2015):

The phenomenon of industrial localization elements cannot be traced without taking in considerations a specific period of time, but a several changes can be occurred in the quantity and quality of industrial environment, some of these changes have great influence on the level of industrial localization, these influences could be negative or positive .

This topic referring to economic indicators like: manpower, wages, production quantity, value of production, (design - available - planned) capacities, value of consumed fuel, medical examinations for personnel, we'll explain deliberately each elements : 


\section{First- manpower}

Manpower is the most important criterion can measure the mass industrial production , but the most distinguished sign is the ability to perform production, this condition is convenient to create industry with one technique level(Patnir.I,1968)

We'll explain also the geographical distribution of the manpower for (Fateh \& Kadhimiya) factories for woven -patterned acrylic blanket industry in Baghdad for (20092015)

\section{Table (1)}

Increasing The manpower of (Fateh \& Kadhimiya) factories and The total amount for (20092015)

\begin{tabular}{|l|l|l|l|l|}
\hline No & Years & $\begin{array}{l}\text { Number of Fateh } \\
\text { factory manpower }\end{array}$ & $\begin{array}{l}\text { Number of } \\
\text { Kadhimiya factory } \\
\text { manpower }\end{array}$ & $\begin{array}{l}\text { Total amount of both factories } \\
\text { (Fateh \& Kadhimiya) }\end{array}$ \\
\hline 1 & 2009 & 695 & 509 & 1204 \\
\hline 2 & 2010 & 588 & 450 & 1038 \\
\hline 3 & 2011 & 534 & 458 & 992 \\
\hline 4 & 2012 & 518 & 430 & 948 \\
\hline 5 & 2013 & 450 & 419 & 869 \\
\hline 6 & 2014 & 335 & 22 & 587 \\
\hline 7 & 2015 & 312 & 213 & 525 \\
\hline
\end{tabular}

The field of study to the general company and two factories (Fateh \& Kadhimiya) in 1/4/2016.

Table(2)

Workers wages of (Fateh \& Kadhimiya) factories for (2009-2015)

\begin{tabular}{|l|l|l|l|l|}
\hline No. & Years & $\begin{array}{l}\text { Workers wages of } \\
\text { Fateh factory } \\
\text { /currency } \\
\text { one thousand Dinar }\end{array}$ & $\begin{array}{l}\text { Workers wages of } \\
\text { Kadhimiya factory } \\
\text { /currency one thousand } \\
\text { Dinar }\end{array}$ & $\begin{array}{l}\text { Total amount of workers } \\
\text { wages for both factories } \\
\text { (Fateh \& Kadhimiya) }\end{array}$ \\
\hline 1 & 2009 & 5089243 & 3776084 & 886537 \\
\hline 2 & 2010 & 4865004 & 4101153 & 8966157 \\
\hline 3 & 2011 & 4384957 & 3575731 & 7960688 \\
\hline 4 & 2012 & 3879845 & 3442560 & 7322405 \\
\hline 5 & 2013 & 3653837 & 3053029 & 6706866 \\
\hline 6 & 2014 & 3168702 & 2377244 & 5545946 \\
\hline 7 & 2015 & 2853367 & 1970273 & 4823640 \\
\hline
\end{tabular}

The researcher rely on unpublished data, accounting department, the expenses for two factories ( Fateh \& Kadhimiya) in 1/4/2016.

Table (1) shows increasing of manpower for those factories, the results indicate that (Fateh) factory take number one for all the years in Arithmetic Mean (490,28571) according to timeline, as it illustrated in the study, while Kadhimiya factory come in second level in Arithmetic Mean (390, 14286), table (8), and map (2). 


\section{Second : Workers wages:}

The labor is social event and great issue, as we know intense labor means a flourished economy, if there are no enough job opportunities for every one the nations will not reach to the highest status. the workers can be rewarded for their efforts by wages (Saleh\& Al Dabbagh,1993)., not to mention the wages will give hard worker the motivation to raise his efforts and keep the work and production process continue in progress(1.L.O,1956).

table (2) shows the evolution of workers' wages, the results indicates that the wage rate of workers for Fateh factory is higher than Kadhimiya factory, the Arithmetic Mean for the first one is $(3984993,57143)$ while the Arithmetic Mean of the second factory was $(3185153,42857)$, table (8) and map (2).

\section{Table (3)}

The quantity of production of (Fateh and Kadhimiya) factories for (2009-2015)/ number

\begin{tabular}{|l|l|l|l|l|}
\hline No & Years & $\begin{array}{l}\text { Quantity of production } \\
\text { for Fateh factory } \\
\text { /number }\end{array}$ & $\begin{array}{l}\text { Quantity of production for } \\
\text { kadhimiya factory / number }\end{array}$ & $\begin{array}{l}\text { Gross amount of two } \\
\text { factories }\end{array}$ \\
\hline 1 & 2009 & 216053 & 15541 & 371494 \\
\hline 2 & 2010 & 43457 & 86426 & 129883 \\
\hline 3 & 2011 & 37668 & 18503 & 56171 \\
\hline 4 & 2012 & 18379 & 25658 & 44037 \\
\hline 5 & 2013 & 10860 & 7900 & 18760 \\
\hline 6 & 2014 & 81640 & 79539 & 161179 \\
\hline 7 & 2015 & 25991 & 16617 & 42608 \\
\hline
\end{tabular}

The researcher rely on unpublished data for two factories ( Fateh \& Kadhimiya) in 1/4/2016.

Table (4)

Value of industrial production of (Fateh and kadhimiya) factories for (2009-2015)/ thousand Dinar

\begin{tabular}{|l|l|l|l|l|}
\hline No & Years & $\begin{array}{l}\text { Value of production for } \\
\text { Fateh factory /number }\end{array}$ & $\begin{array}{l}\text { Value of production for } \\
\text { kadhimiya factory / number }\end{array}$ & $\begin{array}{l}\text { Gross amount of two } \\
\text { factories }\end{array}$ \\
\hline 1 & 2009 & 5242403 & 3486877 & 8729280 \\
\hline 2 & 2010 & 845668 & 1616876 & 2462544 \\
\hline 3 & 2011 & 777163 & 517334 & 1294497 \\
\hline 4 & 2012 & 453702 & 525994 & 979696 \\
\hline 5 & 2013 & 2677572 & 185151 & 452723 \\
\hline 6 & 2014 & 1914992 & 1910810 & 3837790 \\
\hline 7 & 2015 & 592530 & 307660 & 900190 \\
\hline
\end{tabular}

The researcher rely on unpublished data for ( Fateh \& Kadhimiya) factories in 1/4/2016.

\section{Third: quantity of industrial production:}

Table (3) shows the increasing level of production for (Fateh \& Kadhimiya) factories, but (Fateh) factory was in the lead for the years of study (2009-2015) except two years (2010 \& 2012) when it witnessed production recession due to two reasons first one: lack of demand on the products and the second reason is increasing the hours of power outage, then come (Kadhimiya) factory in second place regarding production process 
during the years of study (2009-2015) except two years (2010 \& 2012) it witnessed flourish in the production level because of increasing the demand on the products from several ministries such as (health, interior, defense ministry), the arithmetic mean of two factories Respectively is $(62006,85714)(55726,28571)$. as it shown in table (8) and map (2) show.

\section{Fourth: Value of industrial production:}

We can use the element of value as criterion that has several features to measure the industrial quantity, in industry field the value is calculating by (5) elements, one of those is value of industrial production( Alsamak,2008), table (4) shows the value of industrial production of (Fateh \& Kadhimiya) factories for the years of study (20092015), it turns out that (Fateh ) factory is on the summit for all the years except two years (2010 \& 2012)when these two years witnessed a recession of production as we explained the reasons above, and (Kadhimiya) factory comes in second place, on the contrary, the years (2010 \& 2012) witnessed an increasing on the production, for the same reason we mentioned it before, the Arithmetic Mean is (1223243 \& 14286 , 144200 \& 28571) Respectively, as it indicated in table (8) and map (2).

\section{Fifth : The production capacity:}

This include as follow (Guide of economic \& planning terms ,1980).

\section{A- Design Production capacity:}

Can be measured within a certain period of time and the machine will be designed and built according to the factory specification , this also apply on the other conditions such as maintenance and training and other production requirements.

\section{B- The available production capacity:}

represent the capacity of production during period of time, assuming the availability of all the operating requirements.

\section{C- value of planned production capacity:}

It is bunch of activities that can determine the way of achieving the desired goals if we invest the available resources perfectly .

table (5) show types of production capacity values, vary from each values of (designavailable- planned) Production capacity for (Fateh \& Kadhimiya) factories, due to lack of some conditions concern the operating or production process, table (8) and map ( 2 ) illustrate the extracted arithmetic mean for two factories according to values of : (design , available -planned) capacities, the arithmetic mean of Fateh factory is respectively (5778 and ......, 3133 and 14286, 27836 and .......), as for Kadhimiya factory is respectively (4224 and 88114,2742 and 95514,17486 and 93314).

\section{Sixth: Value of consumed fuel:}

The principles resources to the industries of Iraq are : fuel, electricity- natural gas (Hameed ,2000). 
Table (5)

values of production capacities for (Fateh and Kadhimiya) factories for (2009-2015)/ thousand Dinar

\begin{tabular}{|l|l|l|l|l|l|l|l|}
\hline \multirow{2}{*}{ N } & \multirow{3}{*}{ Years } & \multicolumn{4}{|l|}{ Fateh factory } & \multicolumn{4}{l|}{ Kadhimiya factory } \\
\cline { 3 - 7 } & & $\begin{array}{l}\text { Design } \\
\text { Production }\end{array}$ & $\begin{array}{l}\text { Available } \\
\text { Production }\end{array}$ & $\begin{array}{l}\text { Planed } \\
\text { Production }\end{array}$ & $\begin{array}{l}\text { Design } \\
\text { Production }\end{array}$ & $\begin{array}{l}\text { Available } \\
\text { Production }\end{array}$ & $\begin{array}{l}\text { Planed } \\
\text { Production }\end{array}$ \\
\hline 1 & 2009 & 38900 & 3122 & 8210 & 26250 & 3175 & 6250 \\
\hline 2 & 2010 & 38400 & 3552 & 8000 & 26250 & 3175 & 6250 \\
\hline 3 & 2011 & 38400 & 3552 & 6400 & 28350 & 3429 & 5400 \\
\hline 4 & 2012 & 19200 & 1776 & 3936 & 14175 & 17145 & 27540 \\
\hline 5 & 2013 & 9600 & 888 & 1888 & 7087500 & 857250 & 1323 \\
\hline 6 & 2014 & 14352 & 5712 & 4512 & 13440 & 4536 & 4320 \\
\hline 7 & 2015 & 36000 & 3330 & 7500 & 68560 & 23139 & 32771 \\
\hline
\end{tabular}

The researcher rely on unpublished data for (Fateh \& Kadhimiya) factories in 1/4/2016.

We should recognize between the fuel and energy, for instance coal consider kind of fuel because it generate electrical or vaporous power during the combustion (Aldeib,1977) the values of consumed fuels vary between two factories, depending on the amount of consumed fuel in each factory, table (6) shows the value of consumed fuel in Fateh factory for all the years of study is higher than Kadhimiya factory .because the production amount of Fateh factory is more than Kadhimiya factory, the values were analyzed statistically and the extracted arithmetic mean for two factories is respectively :

(23104 and 42857, 45650 and 71429), as it showed in table (8) and map (2).

\section{Seventh : Medical test for workers:}

The worker hygiene and the way of treating infection and diseases caused by environment of industry is one of important thing. currently the major modern industries do their best to handle this crucial situation, for example in the past, the businessmen and firms owners didn't care much about the worker's health or even didn't bother themselves to improve workers conditions, all they care about is how to benefit from the worker and how to exploit them, and if the workers get sick or couldn't give the same efforts like before or become incapable to work properly, the businessmen will replace them(Remdhan,1984) . table (A7) and (B7) shows the vocational disease of Fateh factory is more than Kadhimiya factory, because the number of workers in Fateh factory is more than Kadhimiya factory, and also the production and consumed fuel in Fateh factory is more than Kadhimiya factory, all these facts and results demonstrate that Fateh factory workers are more vulnerable to vocational diseases especially if the workers do not follow safety instructions, table (8) shows the extracted arithmetic mean from the statistical analysis is respectively ( 8 and 42857, 14 and ........) as it showed in map (2). 
Table (6)

values of consumed fuel for (Fateh \& Kadhimiya) factory for (2009-2015) / (Thousand Dinar)

\begin{tabular}{|l|l|l|l|l|}
\hline N & Years & $\begin{array}{l}\text { Value of consumed fuel } \\
\text { for (Fateh) factory }\end{array}$ & $\begin{array}{l}\text { Value of consumed fuel } \\
\text { for (Kadhimiya) factory }\end{array}$ & $\begin{array}{l}\text { Gross of fuel values } \\
\text { of two factories }\end{array}$ \\
\hline 1 & 2009 & 58998 & 17514 & 76512 \\
\hline 2 & 2010 & 57629 & 16710 & 74339 \\
\hline 3 & 2011 & 71088 & 30864 & 101952 \\
\hline 4 & 2012 & 82203 & 41084 & 83287 \\
\hline 5 & 2013 & 31160 & 48511 & 79671 \\
\hline 6 & 2014 & 8974 & 3955 & 12929 \\
\hline 7 & 2015 & 9503 & 3093 & 12596 \\
\hline
\end{tabular}

The researcher rely on unpublished data for (Fateh \& Kadhimiya) Factories in 1/4/2016.

Table (7A)

Medical vocational examinations for (Fateh) factory for (2009-2015)

\begin{tabular}{|c|c|c|c|c|c|c|c|c|c|c|}
\hline Z & ¿્స & 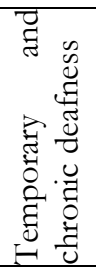 & 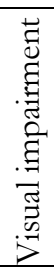 & 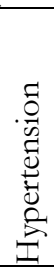 & 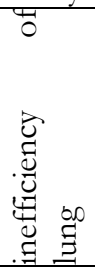 & 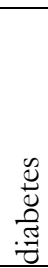 & 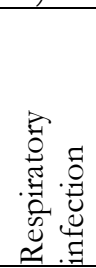 & $\begin{array}{l}\tilde{U} \\
\tilde{U} \\
\tilde{\pi} \\
\tilde{\pi} \\
\oplus\end{array}$ & 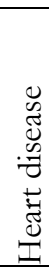 & $\underset{\mathscr{U}}{\mathscr{E}}$ \\
\hline 1 & 2009 & 2 & 2 & 2 & 1 & 2 & - & - & - & - \\
\hline 2 & 2010 & 1 & 2 & 2 & 2 & - & - & 1 & - & - \\
\hline 3 & 2011 & 2 & 2 & 3 & 1 & 1 & 1 & 1 & - & 1 \\
\hline 4 & 2012 & 1 & - & 4 & - & - & - & 1 & 1 & 1 \\
\hline 5 & 2013 & 2 & 1 & 2 & 1 & - & - & - & - & - \\
\hline 6 & 2014 & 3 & 2 & 1 & 1 & - & - & - & - & - \\
\hline 7 & 2015 & 1 & 2 & 1 & 1 & 1 & 2 & 1 & - & - \\
\hline
\end{tabular}

The researcher rely on unpublished data for (Fateh) factories in 1/2/2016.

Table (7B)

Medical vocational examinations for (Kadhimiya) factory for (2009-2015)

\begin{tabular}{|c|c|c|c|c|c|c|c|c|c|c|}
\hline Z & $\overbrace{\overparen{D}}^{\infty}$ & 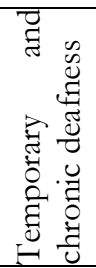 & 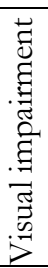 & 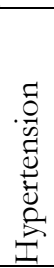 & 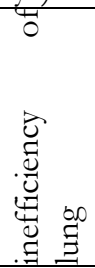 & 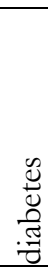 & 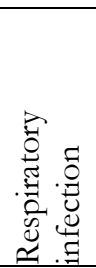 & 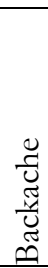 & 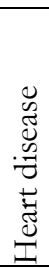 & 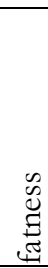 \\
\hline 1 & 2009 & 2 & 2 & 1 & 1 & 1 & 2 & - & - & - \\
\hline 2 & 2010 & 9 & 1 & 2 & - & - & 1 & 1 & 1 & - \\
\hline 3 & 2011 & 6 & 3 & 1 & 7 & - & - & 4 & - & 1 \\
\hline 4 & 2012 & 1 & - & - & - & - & - & - & - & - \\
\hline 5 & 2013 & 4 & 3 & - & 1 & 1 & - & - & - & 1 \\
\hline 6 & 2014 & 6 & 3 & 3 & 1 & - & 1 & - & 2 & 2 \\
\hline 7 & 2015 & 3 & 4 & 1 & 3 & - & 1 & 1 & - & 1 \\
\hline
\end{tabular}

The researcher rely on unpublished data for (Kadhimiya) factories in 1/2/2016. 
Table (8)

The arithmetic mean and standard deviation of economic elements for (Fateh and Kadhimiya) factories, Baghdad , (2009-2015)

\begin{tabular}{|c|c|c|c|c|c|}
\hline \multirow[b]{2}{*}{$\mathrm{N}$} & \multirow[b]{2}{*}{ Factors } & \multicolumn{2}{|l|}{ Fateh Factory } & \multicolumn{2}{|c|}{ Kadhimiya factory } \\
\hline & & $\begin{array}{l}\text { Arithmetic } \\
\text { Mean }\end{array}$ & $\begin{array}{l}\text { Standard } \\
\text { deviation }\end{array}$ & $\begin{array}{l}\text { Arithmetic } \\
\text { Mean }\end{array}$ & $\begin{array}{l}\text { Standard } \\
\text { deviation }\end{array}$ \\
\hline 1 & No. of workers & 490.28571 & 146.416903 & 390.14286 & 111.951520 \\
\hline 2 & Workers wages & 3984993.57143 & 838787.559786 & 3185153.42857 & 769542.299229 \\
\hline 3 & $\begin{array}{ll}\text { Amount } & \text { of } \\
\text { Industrial } \\
\text { Production }\end{array}$ & 62006.85714 & 71727.129687 & 55726.28571 & 54097.299229 \\
\hline 4 & $\begin{array}{l}\text { Value of Industrial } \\
\text { Production }\end{array}$ & 1442004.28571 & 1727935.239138 & 1223243.14286 & 1201996.306620 \\
\hline & $\begin{array}{l}\text { Designated } \\
\text { Production } \\
\text { Capacity }\end{array}$ & 27836.00000 & 129117.750269 & 17486.93314 & 6310.386143 \\
\hline 5 & $\begin{array}{l}\text { Available } \\
\text { Production } \\
\text { Capacity } \\
\end{array}$ & 3133.14286 & 1523.305991 & 2742.95514 & 1214.952277 \\
\hline & $\begin{array}{l}\text { Planned } \\
\text { Production } \\
\text { Capacity }\end{array}$ & 5778.00000 & 2392.066610 & 4224.88114 & 1874.154494 \\
\hline 6 & $\begin{array}{l}\text { Value of } \\
\text { Consumed Fuel }\end{array}$ & 45650.71429 & 23104.42857 & 23104.42857 & 17645.912207 \\
\hline 7 & $\begin{array}{ll}\text { Medical } & \text { and } \\
\text { vocational } & \\
\text { examinations } & \text { for } \\
\text { worker } & \end{array}$ & 14.00000 & 7.615773 & 8.42857 & 2.636737 \\
\hline
\end{tabular}

The researcher works on (statistical program spss ) and adopt also the results of the following tables $(1,2,3,4,5,6,7 \mathrm{~A}, 7 \mathrm{~B})$

\section{Statistical analysis of economic factors for (Fateh and Kadhimiya) factories in Baghdad for (2009-2015)}

The strength and type of relation among each factor of economic factors are measured in chronological order for (Fateh and Kadhimiya) factories for (2009-2015).

But by applying Pearson's Correlation Coefficient the result of statistical analysis show us there is positive, strong, statistical and incorporeal relation at level(1\%) which means there is increase one percent in one of those factories may lead to growing demand on the manpower of the other factory ,from another hand the comparison of workers' wages between (Fateh and Kadhimiya) factories demonstrate there is connection and positive ,strong, statistical incorporeal relation at the level $(1 \%)$ which means there is increase in wages of workers of Fateh factory may lead also to increase in Kadhimiya factory, it worth mentioning there is no Statistical correlation between the manpower of Fateh factory and the wages of workers of Kadhimiya and vice versa.

\footnotetext{
${ }^{*}$ There is strong incorporeal statistical value at level (1\%).
} 
As for the quantity of industrial production of both factories, it shows there is positive ,strong, statistical and incorporeal relation at the level $(1 \%)$, which means there is increase in the quantity of production of Fateh factory may lead to increase in Kadhimiya factory,but it turns out there is no correlation between the quantity of industrial production of Fateh factory and the wages of workers of Kadhimiya factory, and vice versa ${ }^{* *}$

Table (9) result of $t$ test for economic factors of (Fateh and Kadhimiya) factories in Baghdad for (2009-2015)

\begin{tabular}{|l|l|l|l|l|}
\hline \multirow{2}{*}{ No } & \multirow{2}{*}{ Economic factors } & \multicolumn{3}{|l|}{ (Fateh and Kadhimiya) factories } \\
\cline { 3 - 5 } & & T. test & $\begin{array}{l}\text { Degree } \\
\text { freedom }\end{array}$ & Incorporeal degree \\
\hline 1 & No. manpower & 1.501 & 12 & 0.159 \\
\hline 2 & Workers wages & 1.859 & 12 & 0.088 \\
\hline 3 & $\begin{array}{l}\text { Amount of Industrial } \\
\text { production }\end{array}$ & 0.185 & 12 & 0.856 \\
\hline 4 & Value of Industrial production & 0.272 & 12 & 0.790 \\
\hline \multirow{3}{*}{5} & Designated Production Capacity & 1.720 & 12 & 0.11 \\
\cline { 2 - 5 } & Available Production Capacity & 606 & 12 & 0.530 \\
\cline { 2 - 5 } & Planned Production Capacity & 1.352 & 12 & 0.201 \\
\hline 6 & Value of consumed fuel & 1.742 & 12 & 0.107 \\
\hline 7 & $\begin{array}{l}\text { Medical and vocational } \\
\text { examinations for workers }\end{array}$ & 1.829 & 12 & 0.092 \\
\hline
\end{tabular}

The researcher works on (statistical program spss ) and adopt also the results of the following tables $(1,2,3,4,5,6,7 \mathrm{~A}, 7 \mathrm{~B})$.

When we analyze the tables $(1,2,3,4,5,6,7 \mathrm{a}, 7 \mathrm{~b})$ we'll find the arithmetic mean and standard deviation for elements: manpower - wages of workers, quantity of production value of production - value of (design, available, planned ) capacities - value of consumed fuel and medical and vocational examinations for workers, is respectively by applying t-test for correlated samples, the results like it indicated in tables (8 and 9) for economic factors .

The result measured by t-test is (1 and 501) by degree of freedom (12) and Incorporeal degree less than $(5 \%)$ is ( 0 and 159) that means there is statistical incorporeal deference in the manpower element between (Fateh and Kadhimiya) factories by using arithmetic mean and standard deviation which is respectively (390 and 14286, 490 and 28571) and (111 and 951520,146 and 416903).

The comparison had been made between the workers wages of two factories, the result measured by t-test is: (1 and 859) by degree of freedom (12) and Incorporeal degree less than $(5 \%)$ is $(0$ and 088$)$. this means there is a statistical incorporeal deference in the element of workers wages of two factories, the arithmetic mean and standard deviation, is respectively (3185153 and 42857, 3984993 and 571413) and (769542 and 299308, 838787 and 559786), and the comparison in the amount of production between two factories, the result measured by t-test is $(0$ and 185) by degree of freedom (12) and

\footnotetext{
${ }^{* * *}$ There is weak incorporeal statistical value at level (5\%).
} 
Incorporeal degree less than $(5 \%)$ is $(0$ and 856$)$, this means there is a statistical incorporeal deference in the element amount of industrial production for two factories, the arithmetic mean and standard deviation, is respectively (55726 and 28571, 62006 and 85714) and (54097 and 299229, 71727 and 126987).

As for value of industrial production measured by t-test is ( 0 and 272) by degree of freedom (12) and Incorporeal degree less than (5\%) is (0 and 790), this means there is a statistical incorporeal deference between the element of industrial production value of two factories . the arithmetic mean and standard deviation, is respectively (1223243 and 14286,1442004 and 28571) and (1201996 and 306620, 1757935 and 239138) .

As for capacity value, it refer to value of industrial production for two factories has a correlation and positive, strong and incorporeal relation at level (1\%) and there is no statistical relation between industrial production value and consumed fuel value in Fateh factory .

From other hand Kadhimiya factory got negative result regarding the same element , this lead to conclusion( if there any increase in one of the variables will lead to decrease into other variable), for the element of capacities value, there is no statistical relation for design capacity between (Fateh \& Kadhimiya) factory . for the value of available capacity for both factories, it turn out there is correlation and positive, strong, statistical and incorporeal relation at level $(1 \%)$, the statistical analysis shows there is positive, weak, statistical, incorporeal and statistical relation between (Fateh and Kadhimiya) factories.

Finally we reach to a result through the statistical analysis for two factories, that there is no statistical relation between (Fateh and Kadhimiya) factories.

The three types (design, available, planned) capacities are measured by $\mathrm{t}$-test, the result are respectively (1 and 352, 606, 1 and 720) by degree of freedom (12) and Incorporeal degree less than (5\%) to be (0 and 201, 0 and 530, 0 and 111), this means there is a statistical incorporeal deference in the three types of capacities for two factories . the arithmetic mean and standard deviation, is respectively (4224 and 88114, 2742 and 95514,17486 and 93314,5778 and ......., 3133 and 14286,27836 and ........) and (1874 and 154494, 1214 and 952277,9310 and 386143,2392 and 066610, 1523 and 305991 , 12917 and 750269).

A comparison had been made between two factories about the values of consumed fuel , the result measured by T-test is (1 and 742) ) by degree of freedom (12) and Incorporeal degree less than $(5 \%)$ is $(0$ and 107) this means there is a statistical incorporeal deference for two factories . the arithmetic mean and standard deviation, is respectively (23104 and 42857, 45650 and 71429), (17645 and 912207, 23104 and 42857), finally we made a comparison in medical and vocational examinations for workers between two factories, the t-test is (1 and 829$)$ by degree of freedom (12) and Incorporeal degree less than $(5 \%)$ to be $(0$ and 092). this means there is a statistical incorporeal deference for tow factories the arithmetic mean and standard deviation, respectively is ( 8 and 42857, 14 and 0000) and ( 2 and 636737, 7 and 6157730).

The groups of economic factors are statistically analyzed for both factories, the total number of manpower for (Fateh \& Kadhimiya) factories and the gross amount of workers' wages referred there is positive, strong, statistical and incorporeal correlation at level $(1 \%)$, it also appear there is positive ,strong, statistical and incorporeal correlation 
at level $(1 \%)$ between the amount of industrial production and the value of industrial production. there is no relation between the design and planned capacity at level (1\%), while it appear in the same time a positive strong, statistical and incorporeal correlation at level $(1 \%)$ between the design and planned capacity for (Fateh and Kadhimiya) factories, and there is no statistical relation between value of consumed fuel and medical , vocational examinations for workers at level $(1 \%)$, the result was negative meaning if there is any increase in one of the variables will definitely lead to decreasing for other variable.

\section{Conclusions:}

1- Both factories ( Al- Fateh and Al- Kadhimeya) are situated on a suitable location according to industrial settlement factors but it need rehabilitation, development and maintenance.

2- The two kinds of stitched and woven blankets must be marketed to the ministries and public companies in addition to direct selling to the people through the fairs of the two factories.

3- Al- Fateh factory surpassed Al- Kadhimeya Factory through quantitative and statistical analysis for research study period (2009-2015) out of all research data.

\section{The Proposals}

1- Both factories need government product especially by supplying electric power which lead to reduce the product prices.

2- Increase the attention, care and edification for national product through media and publicity mea ns by financial allocation for these factories.

3- Increase awareness among the employees and health care and education for vocational safety .

\section{References}

Ahmed Ali Saleh \& Isam Abdulwahab Al Dabbagh, Administration of Human Resources, Khelood printing house, 1993, Baghdad.

Abdulmuttaleb Abdulhameed, Economic feasibility to make investment decisions, Hurreeya printing house, Baghdad, 2000.

Muhammed Azher Alsamak, geography of industry with contemporaneous perspective, Ibn Al Atheer for printing house and publishing, Mosul university , 2008.

Mohammed Mahmood Ibraheem Aldeib , economic geography, printing house of Saeed Rafet, first edition, Cairo, 1977.

Al Saied Remdhan, accidents of industry and Industrial Safety, bureau of Al Jamei Al Hadeeth, Alexandria , 1984.

Patnir. I, a new methods for measuring location changes in a manufacturing industry economic Geography,1968.

I.L.o, problem of wages policy in Asian countries, Geneva.1956.

Guide of Economic and planning terminologies, ministry of planning, national institute for planning, , printing house of the central bureau for statistic, Baghdad, 1988.

General company for fabric and leather industries, Baghdad.

Fateh \& Kadhimiya factories. 
